\title{
Gravitational Field Intensity and Shifting of Waves
}

\author{
Sankar Palchoudhury \\ 101/673/A, College Para, P.O. Kharia, Ward No. 21, Dist. Jalpaiguri, Pin Code - 735101, West Bengal, India \\ Email: sankarpalchoudhury@gmail.com
}

Received Oct 2020

Received in revised: Dec 2020

Published: Dec 2020

\begin{abstract}
The celestial bodies like the sun, stars, etc., are the owner of higher gravitational field intensity areas and the source of various kinds of waves. Waves rush from higher gravitational field intensity areas like the sun to lower gravitational field intensity areas like the earth. This paper, finding out that the wave exchanges some force during traveling from the sun to the ground. Every wave has a frequency and each frequency of a wave has two parts, crest and trough and both together is a complete single frequency.
\end{abstract}

Keywords: Generate, Crest, Trough, Frequency, Fraction.

C2020 The Authors. Published by Fundamental Journals. This is an open access article under the CC BY-NC https://creativecommons.org/licenses/by-nc/4.0/

https://doi.org/10.14331/ijfps.2020.330142

\section{INTRODUCTION}

As we know every frequency of a wave contains two parts, one is a crest, and the other is a trough (Fig 1). A wave occurs due to some disturbances in the gravitational field (Palchoudhury, 2020). It is clear that, a complete wave has two steps-one is a crest, and the other is a trough. Only on a crest or a trough, a wave is a incomplete wave and cannot move forward. Counting of frequency is depends on every complete wave. So, the frequency cannot be less than one and fraction. The gravitational field is always quiet and waves are less, if disturbance does not arise. We may define the nature of a wave as follows as a man walks, first, right step and next, left step, and both measures together is a complete walk. So, a wave moves the first crest and next, trough and both together is an entire wave. Crest and trough, both together is a wave as well as a number of frequency.

A man cannot move only on either right step or left step that is a fraction step. A wave cannot move only on either crest or trough that is a fraction of a wave. A complete cycle is a complete frequency. Frequency must be an integer number, not fraction. A person walks at different lengths with the parity of their height and power. Same, a wave moves with the parity of the wavelength, height (amplitude) and power. Number of frequency cannot be less than one. According to the velocity of light, the wavelength of a wave even gravitational wave cannot be longer than light velocity $(c)$. 
The wave propagates in the gravitational field depending on the gravitational field intensity. The shifting of wavelength, amplitude, frequency and power of a wave is depends on the gravitational field intensity (Palchoudhury, 2020).

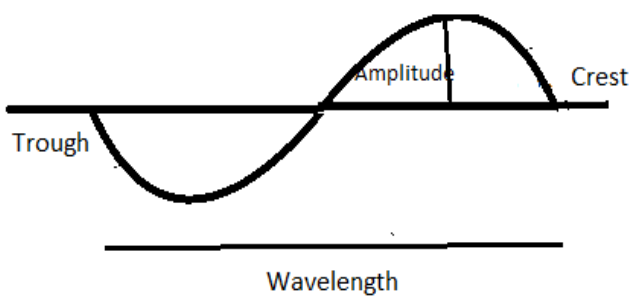

Fig.1 Wave frequency

\section{WAVES SHIFTING}

Waves run from the higher gravitational field intensity area to reduce intensity area. When waves rush from higher intensity to lower intensity area, then waves lose some force in this propagation (Table 1). According to the Palchoudhury Wave theory (Palchoudhury, 2020), massive and heavy celestial bodies like the sun, stars, etc., are the owner of a higher gravitational field intensity area. Massive stars (like sun and etc.) are the source of the various kinds of waves. Waves rush from higher gravitational field intensity areas (like the sun) to lower gravitational field intensity areas (like earth). And waves exchange some force during propagation. The waves travel from higher gravitational field intensity areas to decline, and then waves lose some power (see Table1).

Common primary data of various waves, for example, the wavelength range of color red $(\sim 625-740 \mathrm{~nm})$, orange $(\sim 590$ - $625 \mathrm{~nm})$, yellow $(\sim 565-590 \mathrm{~nm})$, green $(\sim 500-565 \mathrm{~nm})$, blue $(\sim 450-485 \mathrm{~nm})$, violet $(\sim 380-450 \mathrm{~nm})$, Infrared wave $(\sim 750 \mathrm{~nm}-1 \mathrm{~mm})$, Band wave $(\sim 1260-1675 \mathrm{~nm})$, Radio wave $(1 \mathrm{~m}-100 \mathrm{~km})$, Microwave $(\sim 1 \mathrm{~mm}-1 \mathrm{~m})$, Ultraviolet wave $(\sim 10-400 \mathrm{~nm})$, X-ray wave $(\sim 0.01-10 \mathrm{~nm})$, Original Band ( 1260 - 1360), Extended Band ( 13660 - 1460), Short length Band ( 1460 - 1530), Conventional Band ( 1530 1565), Long-wavelength Band ( 1565 - 1625), Ultra long wavelength Band ( 1625 - $1675 \mathrm{~nm})$ and Gamma-ray $(\sim<$ $\left.10^{-11} \mathrm{~m}\right)$. (NCERTS) And data verify in calculators-Length Converter, Convert Electron-volt to Newton Meter, Energy converter and use in the tables.

Table.1 Various Waves and its local area force per second

\begin{tabular}{|c|c|c|c|c|c|c|c|}
\hline \multirow{2}{*}{ Different Wave } & \multicolumn{3}{|c|}{ Unit Wave } & \multirow{2}{*}{$f$} & \multicolumn{2}{|c|}{ Local Area Force at } & \multirow{2}{*}{$\begin{array}{c}\text { Waves lose force } \\
\text { at Earth } \\
\text { (Sun - Earth) }\end{array}$} \\
\hline & $\lambda$ & $\dot{A}$ & $F$ & & Sun & Earth & \\
\hline Red & $6.86 \mathrm{E}-07$ & $2.42 \mathrm{E}-07$ & $6.64 \mathrm{E}-34$ & $4.37 \mathrm{E}+14$ & 8.11E-18 & $2.90 \mathrm{E}-19$ & $7.82 \mathrm{E}-18$ \\
\hline Orange & $6.10 \mathrm{E}-07$ & $2.15 \mathrm{E}-07$ & $6.62 \mathrm{E}-34$ & $4.91 \mathrm{E}+14$ & $9.10 \mathrm{E}-18$ & $3.26 \mathrm{E}-19$ & $8.78 \mathrm{E}-18$ \\
\hline Yellow & $5.80 \mathrm{E}-07$ & $2.05 \mathrm{E}-07$ & $6.64 \mathrm{E}-34$ & $5.17 \mathrm{E}+14$ & $9.60 \mathrm{E}-18$ & $3.43 \mathrm{E}-19$ & $9.26 \mathrm{E}-18$ \\
\hline Green & $5.47 \mathrm{E}-07$ & $1.93 \mathrm{E}-07$ & $6.64 \mathrm{E}-34$ & $5.48 \mathrm{E}+14$ & $1.02 \mathrm{E}-17$ & $3.64 \mathrm{E}-19$ & $9.81 \mathrm{E}-18$ \\
\hline Blue & 4.78E-07 & $1.68 \mathrm{E}-07$ & $6.62 \mathrm{E}-34$ & $6.27 \mathrm{E}+14$ & $1.16 \mathrm{E}-17$ & $4.15 \mathrm{E}-19$ & $1.12 \mathrm{E}-17$ \\
\hline Violet & 4.27E-07 & $1.50 \mathrm{E}-07$ & $6.63 \mathrm{E}-34$ & $7.02 \mathrm{E}+14$ & $1.30 \mathrm{E}-17$ & $4.65 \mathrm{E}-19$ & $1.25 \mathrm{E}-17$ \\
\hline Near Infrared & $9.60 \mathrm{E}-07$ & $3.38 \mathrm{E}-07$ & $6.62 \mathrm{E}-34$ & $3.12 \mathrm{E}+14$ & $5.78 \mathrm{E}-18$ & $2.07 \mathrm{E}-19$ & $5.57 \mathrm{E}-18$ \\
\hline Short Wavelength IR & $2.00 \mathrm{E}-06$ & 7.04E-07 & $6.63 \mathrm{E}-34$ & $1.50 \mathrm{E}+14$ & $2.78 \mathrm{E}-18$ & $9.93 \mathrm{E}-20$ & $2.68 \mathrm{E}-18$ \\
\hline Mid Wavelength IR & $5.00 \mathrm{E}-06$ & $1.76 \mathrm{E}-06$ & $6.63 \mathrm{E}-34$ & $6.00 \mathrm{E}+13$ & $1.11 \mathrm{E}-18$ & $3.97 \mathrm{E}-20$ & $1.07 \mathrm{E}-18$ \\
\hline Long Wavelength IR & $1.20 \mathrm{E}-05$ & 4.23E-06 & $6.62 \mathrm{E}-34$ & $2.50 \mathrm{E}+13$ & 4.63E-19 & $1.66 \mathrm{E}-20$ & 4.46E-19 \\
\hline Far Infrared & $2.00 \mathrm{E}-04$ & $7.05 \mathrm{E}-05$ & $6.63 \mathrm{E}-34$ & $1.50 \mathrm{E}+12$ & $2.78 \mathrm{E}-20$ & 9.93E-22 & $2.68 \mathrm{E}-20$ \\
\hline Radio & $1.50 \mathrm{E}+02$ & $5.29 \mathrm{E}+01$ & $6.63 \mathrm{E}-34$ & $2.00 \mathrm{E}+06$ & $3.71 \mathrm{E}-26$ & $1.33 \mathrm{E}-27$ & $3.57 \mathrm{E}-26$ \\
\hline Microwave & $5.00 \mathrm{E}-02$ & $1.76 \mathrm{E}-02$ & $6.63 \mathrm{E}-34$ & $6.00 \mathrm{E}+09$ & $1.11 \mathrm{E}-22$ & $3.97 \mathrm{E}-24$ & $1.07 \mathrm{E}-22$ \\
\hline Ultra violate-A & $3.80 \mathrm{E}-07$ & $1.34 \mathrm{E}-07$ & $6.63 \mathrm{E}-34$ & $7.89 \mathrm{E}+14$ & $1.46 \mathrm{E}-17$ & $5.23 \mathrm{E}-19$ & $1.41 \mathrm{E}-17$ \\
\hline Ultra violate $-\mathrm{B}$ & $3.00 \mathrm{E}-07$ & $1.06 \mathrm{E}-07$ & $6.63 \mathrm{E}-34$ & $9.99 \mathrm{E}+14$ & $1.85 \mathrm{E}-17$ & $6.62 \mathrm{E}-19$ & $1.79 \mathrm{E}-17$ \\
\hline Ultra violate $-\mathrm{C}$ & $1.60 \mathrm{E}-07$ & 5.64E-08 & $6.63 \mathrm{E}-34$ & $1.87 \mathrm{E}+15$ & $3.47 \mathrm{E}-17$ & $1.24 \mathrm{E}-18$ & $3.35 \mathrm{E}-17$ \\
\hline X-ray & $1.00 \mathrm{E}-09$ & $3.52 \mathrm{E}-10$ & $6.63 \mathrm{E}-34$ & $3.00 \mathrm{E}+17$ & $5.56 \mathrm{E}-15$ & $1.99 \mathrm{E}-16$ & $5.36 \mathrm{E}-15$ \\
\hline Original Band & $1.31 \mathrm{E}-06$ & $4.60 \mathrm{E}-07$ & $6.63 \mathrm{E}-34$ & $2.30 \mathrm{E}+14$ & $4.26 \mathrm{E}-18$ & $1.52 \mathrm{E}-19$ & 4.10E-18 \\
\hline Extended Band & $1.40 \mathrm{E}-06$ & 4.92E-07 & $6.63 \mathrm{E}-34$ & $2.15 \mathrm{E}+14$ & $3.98 \mathrm{E}-18$ & $1.42 \mathrm{E}-19$ & $3.84 \mathrm{E}-18$ \\
\hline Short wavelength Band & $1.48 \mathrm{E}-06$ & $5.20 \mathrm{E} 07$ & $6.63 \mathrm{E}-34$ & $2.03 \mathrm{E}+14$ & $3.77 \mathrm{E}-18$ & $1.35 \mathrm{E}-19$ & 3.63E-18 \\
\hline Conventional Band & $1.54 \mathrm{E}-06$ & $5.42 \mathrm{E}-07$ & $6.63 \mathrm{E}-34$ & $1.95 \mathrm{E}+14$ & $3.61 \mathrm{E}-18$ & $1.29 \mathrm{E}-19$ & $3.48 \mathrm{E}-18$ \\
\hline Long wave length Band & $1.60 \mathrm{E}-06$ & 5.64E-07 & $6.63 \mathrm{E}-34$ & $1.87 \mathrm{E}+14$ & $3.47 \mathrm{E}-18$ & $1.24 \mathrm{E}-19$ & $3.35 \mathrm{E}-18$ \\
\hline Ultra long Wave Band & $1.66 \mathrm{E}-06$ & $5.85 \mathrm{E}-07$ & $6.63 \mathrm{E}-34$ & $1.81 \mathrm{E}+14$ & $3.35 \mathrm{E}-18$ & $1.20 \mathrm{E}-19$ & $3.23 \mathrm{E}-18$ \\
\hline Gamma ray & $8.00 \mathrm{E}-12$ & $2.81 \mathrm{E}-12$ & $6.63 \mathrm{E}-34$ & $3.75 \mathrm{E}+19$ & $6.95 \mathrm{E}-13$ & $2.48 \mathrm{E}-14$ & $6.71 \mathrm{E}-13$ \\
\hline Gravitational Wave & $2.99 \mathrm{E}+08$ & $1.03 \mathrm{E}+08$ & $6.48 \mathrm{E}-34$ & $1.00 \mathrm{E}+00$ & $1.81 \mathrm{E}-32$ & $6.48 \mathrm{E}-34$ & $1.75 \mathrm{E}-32$ \\
\hline
\end{tabular}


As we know a black hole is a massive celestial body but it is not a source of waves. Because its gravitational field intensity is too high so that nothing can make a disturbance in its gravitational field and therefore generating waves and so cannot provide waves. In this case, waves cannot spread outwards from their region as well as take entrance into it. Therefore black holes itself is not the source of waves in such a high gravitational field intensity area. Power of an external wave is not enough to make a disturbance for creating waves in such a high gravitational field intensity area.

NGC-205, Constellation-Andromeda, mass in solar unit is $\left(9 \times 10^{4}\right) M_{\odot}$, and with distance $2.3 \times 10^{6} \mathrm{ly}$. (Howley et al., 2008)Spiral galaxy M33 is located in the triangle-shaped constellation Triangulum, earning it the nickname the Triangulum galaxy. About half the size of our Milky Way galaxy, M33 is the third-largest member of our Local Group of galaxies following the Andromeda galaxy (M31) and the Milky Way. Messier-33 mass is about $5 \times 10^{4} M_{\odot}$ and distance $2.6 \times 10^{6}$ ly (NASA, 2019).
Sagittarius $A^{*}\left(\operatorname{Sgr} A^{*}\right)$ is a bright and very compact astronomical radio source at the Galactic Center of the Milky Way. It is located near the border of the constellations Sagittarius and Scorpius, about $5.6^{\circ}$ south of the ecliptic. Sagittarius $A^{*}$ is the location of a supermassive black hole. The mass of $\mathrm{Sgr} \mathrm{A}^{*}$ in solar mass approximately is about $\sim 4.6 \times 10^{6} M_{\odot}$ and distance $2.7 \times 10^{4}$ ly (NASA, 2013; Sten, 2019).

Gravitational field intensity (GFI) of the sun approximately is 28 times greater than the earth. In comparison to the earth's GFI, we can state, the GFI of the black hole is the multiplication of 28 with a solar mass of black hole.

So, the GFI of black holes like NGC-205 is $2.52 \times 10^{5}$. For Messier-33 it is about $1.4 \times 10^{6}$ and for SgrA is $1.29 \times 10^{8}$ times greater than the earth. External and internal power is not enough to make a disturbance for generating waves in the higher gravitational field intensity area of black holes seen in table-II. So, waves cannot spread outwards from it as well as take entrance on it.

Table. 2 Power of Black Holes

\begin{tabular}{|l|c|c|c|c|c|c|c|}
\hline \multirow{2}{*}{ Colours } & \multirow{2}{*}{$\begin{array}{c}\text { Force (P) } \\
\text { retain at earth }\end{array}$} & \multicolumn{4}{|c|}{ Power require to generate waves in the local area of the Black Holes } \\
\cline { 3 - 8 } & & \multicolumn{2}{|c|}{ NGC-205 } & \multicolumn{2}{c|}{ Messier-33 } & \multicolumn{2}{c|}{ SgrA } \\
\cline { 3 - 8 } & & $R$ & $P$ & $R$ & $P$ & $R$ & $P$ \\
\hline Red & $2.90 \mathrm{E}-19$ & $2.52 \mathrm{E}+05$ & $7.31 \mathrm{E}-14$ & $1.40 \mathrm{E}+06$ & $4.06 \mathrm{E}-13$ & $1.29 \mathrm{E}+08$ & $3.74 \mathrm{E}-11$ \\
\hline Orange & $3.25 \mathrm{E}-19$ & $2.52 \mathrm{E}+05$ & $8.20 \mathrm{E}-14$ & $1.40 \mathrm{E}+06$ & $4.55 \mathrm{E}-13$ & $1.29 \mathrm{E}+08$ & $4.19 \mathrm{E}-11$ \\
\hline Yellow & $3.43 \mathrm{E}-19$ & $2.52 \mathrm{E}+05$ & $8.64 \mathrm{E}-14$ & $1.40 \mathrm{E}+06$ & $4.80 \mathrm{E}-13$ & $1.29 \mathrm{E}+08$ & $4.42 \mathrm{E}-11$ \\
\hline Green & $3.64 \mathrm{E}-19$ & $2.52 \mathrm{E}+05$ & $9.17 \mathrm{E}-14$ & $1.40 \mathrm{E}+06$ & $5.09 \mathrm{E}-13$ & $1.29 \mathrm{E}+08$ & $4.68 \mathrm{E}-11$ \\
\hline Blue & $4.15 \mathrm{E}-19$ & $2.52 \mathrm{E}+05$ & $1.05 \mathrm{E}-13$ & $1.40 \mathrm{E}+06$ & $5.81 \mathrm{E}-13$ & $1.29 \mathrm{E}+08$ & $5.34 \mathrm{E}-11$ \\
\hline Violate & $4.65 \mathrm{E}-19$ & $2.52 \mathrm{E}+05$ & $1.17 \mathrm{E}-13$ & $1.40 \mathrm{E}+06$ & $6.50 \mathrm{E}-13$ & $1.29 \mathrm{E}+08$ & $5.98 \mathrm{E}-11$ \\
\hline
\end{tabular}

Here $R$, is the ratio between the black and the gravitational field intensity and $P$ is power. To make a disturbance for generating waves in black hole said above, power requires $10^{5}$ to $10^{8}$ times more than the earth. Due to the lack of enormous power, waves are not available in black holes.

\section{CONCLUSION}

Waves rush from higher gravitational field intensity areas like the sun to lower gravitational field intensity areas like the earth. And waves lose some force in this travel. It is most

\section{REFERENCES}

Howley, K., Geha, M., Guhathakurta, P., Montgomery, R., Laughlin, G., \& Johnston, K. (2008). Darwin tames an andromeda dwarf: unraveling the orbit of NGC 205 using a genetic algorithm. The Astrophysical Journal, 683(2), 722. NASA. (2013). Supermassive Black Hole Sagittarius A*. important findings that the length of a wave, even gravitational waves, cannot be more than light velocity $(c)$ the frequency cannot be less than $1 \mathrm{~Hz}$ or fraction per second.

\section{ACKNOWLEDGEMENT}

I, the author, express sincerely at this moment sincere gratefulness to the Editor-in-Chief, reviewers and editorial staff of the Internal Journal Fundamental Physical Science (IJFPS) for their valuable suggestion for the improvement of the manuscript.

NASA. (2019). Messier 33 (The Triangulum Galaxy). 2019

Palchoudhury, S. (2020). The Wave Nature Phenomena and the Gravitational Field: Physics. International Journal of Fundamental Physical Science, 10(2), 12-15. doi: https://doi.org/10.14331/ijfps.2020.330136

Sten, O. (2019). Black Hole Math NASA (National Aeronautics and Space Administration). 